http://dx.doi.org/10.30681/23588403v14i0108

\title{
PETER SCHLEMIHL E A SOMBRA: ALGUNS VETORES DE PERTENCIMENTO
}

\author{
Dionei MATHIAS (UFSM) ${ }^{1}$ \\ Deborah do Carmo FILIPPETTO (UFSM) ${ }^{2}$
}

Data de recebimento: 09/05/2020

Data de aceite: $29 / 07 / 2020$

\begin{abstract}
Resumo: Este artigo discute o conflito de pertencimento na novela A história maravilhosa de Peter Schlemihl, de Adelbert von Chamisso. Nela, o protagonista Peter Schlemihl vende sua sombra em troca de recursos econômicos inesgotáveis, como forma de obtenção de pertencimento. A falta de sombra, contudo, causa novas dificuldades de aceitação, forçando-o a encontrar outros modos de dissimular sua diferença. Diante desse cenário, esta discussão terá como foco a análise de três vetores de pertencimento na trajetória do protagonista. $\mathrm{O}$ primeiro é o pertencimento de classe, associado com a aquisição de capital econômico e visibilidade pública. O segundo reside em sua busca por pertencimento afetivo, ao tentar estabelecer uma narrativa conjunta com outros personagens significantes. Na última etapa e após seu fracasso nas esferas precedentes, ele busca pertencimento na produção científica. Com base no trabalho de Pfaff-Czarnecka (2011), entendemos pertencimento como um posicionamento social definido por afetividade.
\end{abstract}

Palavras-Chave: Adelbert von Chamisso. A história maravilhosa de Peter Schlemihl. Pertencimento.

\begin{abstract}
This article discusses the conflict of belongingness in Adelbert von Chamisso's novella Peter Schlemihl's Wondrous Story. In this text, the main character Peter Schlemihl sells his shadow in exchange for inexhaustible economic resources, as a way of obtaining the feeling of belongingness. His lack of a shadow, however, causes new difficulties for his acceptance, forcing him to find new ways to conceal his otherness. Thus, this discussion will focus on the analysis of three vectors of belongingness in the protagonist's itinerary. The first lays in class belongingness, associated with the acquisition of economic capital and public visibility. The second resides in his search for affective belongingness, by trying to establish a shared narrative with other significant characters. Finally, after failing in all precedent spheres, he looks for belongingness in scientific research. Based on Pfaff-Czarnecka's (2011) discussion, we understand belongingness as a social positioning defined by affectivity.
\end{abstract}

Keywords: Adelbert von Chamisso. Peter Schlemihl's Wondrous Story. Belongingness.

\section{Introdução}

\footnotetext{
${ }^{1}$ Professor de língua e literatura na Universidade Federal de Santa Maria. Possui formação em Letras pela Universidade de Hamburgo (Grund- und Hauptstudium, Magister Artium, Doktor phil.) e pela Universidade Federal do Paraná (Doutorado em Letras)

${ }^{2}$ Graduanda de Letras Inglês e suas literaturas pela Universidade Federal de Santa Maria. Integrante do projeto "Literatura e Identidade". deborah.filippetto@ gmail.com
} 
Adelbert von Chamisso nasceu em 1781, na França. Quase dez anos mais tarde, a família aristocrática precisou fugir da França por conta das turbulências políticas, em decorrência da Revolução Francesa. A família se estabelece em Berlim, onde o autor morre em 1838. Como estrangeiro, Chamisso se integra na sociedade prussiana, conseguindo fazer carreira no serviço militar e participar da vida literária daquela cultura. Esse é um dos motivos pelos quais seu nome foi escolhido para denominar o Prêmio Chamisso, concedido entre 1985 e 2017 a autores de origem estrangeira que escrevem em alemão. Interessantemente, a crítica, neste caso, tende a não utilizar a palavra "estrangeiro" (“Ausländer”) ou imigrante, preferindo epítetos da inclusão como "prussiano da França" (LAHNSTEIN, 1984), um "cidadão da Europa" (FISCHER, 1990, p. 15) ou o "europeu selvagem", com um toque de coolness (LANGNER, 2008). Autores que foram agraciados com o Prêmio Chamisso, com raras exceções, não tendem a ser vistos nessas modalidades de inclusão.

A despeito dessa contradição nos percursos discursivos, um dos mais famosos textos de Chamisso, a novela fantástica A história maravilhosa de Peter Schlemihl, definitivamente aponta para uma temática muito importante e cara na literatura de fluxos migratórios, a saber, o pertencimento. Nesse caso, obviamente não se trata do pertencimento pautado pelo princípio da inclusão e da participação cultural que caracteriza muitos textos da literatura daqueles que receberam o Prêmio Chamisso, mas uma forma de pertencimento ainda menos focada em quem é imigrante e quem é nativo, isto é, um habilidade de acessar o mundo ainda sem o imperativo do passaporte. O percurso biográfico de Chamisso talvez tenha criado uma sensibilidade para essa problemática e despertado um desejo de criar redes simbólicas para representar essa experiência.

Com efeito, o desejo de pertencimento não se limita a imigrantes ou filhos de imigrantes. Essa temática tem um papel de destaque nesse campo literário, justamente porque as possibilidades de pertencer são constantemente questionadas, mas isso também ocorre em outros contextos da interação humana, representada em textos ficcionais. Pertencimento representa um posicionamento social perpassado de afetividade, segundo Pfaff-Czarnecka (2011, p. 201). Isto é, ao empreender o esforço de tecer uma identidade e construir uma narrativa de representação do si, todo indivíduo se posiciona nas diferentes esferas em que transita, criando configurações de pertencimento nos diferentes espaços de interação. Essa configuração gera dinâmicas de identificação com o grupo ou com parceiros significantes para o respectivo 
indivíduo. A identificação, por sua vez, produz a adaptação da narrativa identitária, de modo a criar uma confluência de interesses e valores.

No plano individual, a busca por pertencimento inclui a criação de vínculos afetivos que preveem uma imaginação de futuro conjunta, em que o casal ou o grupo nuclear insere o respectivo parceiro em sua narrativa pessoal de identidade. Essa modalidade de criação de vínculos produz uma configuração afetiva, em que os diferentes integrantes assumem um certo grau de responsabilidade pelo bem-estar dos parceiros e pela imagem do si, com a qual se representa no espaço de interação. De todas as formas de pertencimento, essa provavelmente é a mais importante, pois ela define vetores de interação no núcleo familiar e posteriormente no relacionamento íntimo. O escopo desse pertencimento vai definir o grau de responsabilidade a ser assumida pelo outro e seu lugar na tessitura de identidade empreendida pelo outro.

Em esferas que transcendem o núcleo familiar e o relacionamento íntimo, pertencimento também se concretiza por meio de investimento afetivo, em grande parte, por meio da simpatia e consequentemente pela concessão de chances. Para que chances sejam concedidas, contudo, o respectivo indivíduo precisa fazer jus às expectativas do grupo ao qual deseja pertencer. Assim, o pertencimento a uma classe social, com sua lógicas específicas de comportamento, de consumo, de valores, etc., exige a posse de determinados capitais e a adaptação da narrativa de identidade, para que esta se aproxime às narrativas consideradas adequadas naquele grupo. Isso não é muito diferente na esfera do pertencimento nacional, onde, contudo, além do passaporte, a exigência de comportamentos afins, em parte também, a semelhança étnica, por vezes se revelam como imprescindíveis.

Quando o indivíduo é confrontado com a negação de suas aspirações de pertencimento, um caminho reside na solidão, isto é, o sujeito interrompe as tentativas de negociação para obter acesso ao grupo e reorganiza sua narrativa pessoal. Outra estratégia reside em criar formas alternativas de pertencimento, criando novas configurações de grupo, em que seus membros tenham experiências semelhantes de negação do pertencimento, ou trançando percursos individuais, em que o sujeito busca administrar suas necessidades afetivas, com base naquilo que está à sua disposição. Esses percursos podem compreender narrativas em que o indivíduo abandona o desejo de pertencer a uma estrutura social (em suas mais diferentes formatações) e passa a focar em outras formas de concretizar a existência, para derivar delas uma identificação existencial que proporcione a sensação de pertencer.

A herança crítica sobre o texto de Chamisso se divide em discussões sobre a sombra enquanto fenômeno físico ou distinção cultural. Nisso, algumas produções se destacam, como 
a de Ralph Flores (1974), Sabine Parmentier (2005) e Christa Knellwolf King (2016). Flores discorre sobre os erros de concepção sobre a prioridade dos valores morais, além da necessidade de sensibilização para as normas que regem um determinado espaço social. Parmentier foca sua análise nos aspectos psicanalíticos da obra de Chamisso, especialmente sobre como ocorre a manifestação do narcisismo primário do protagonista. King, por sua vez, questiona o que constitui a completude de um indivíduo, analisando aspectos relativos à identidade social de Schlemihl e atualizando o significado da falta de sombra.

Nesse sentido, este artigo deseja reler a novela fantástica de Chamisso e discutir como o pertencimento tem um impacto do percurso protagonista. Isso parece ser relevante em três situações: ao buscar pertencimento a um grupo social que detém recursos econômicos, ao tentar criar um relacionamento que lhe proporcione estabilidade e ao investir suas energias no trabalho científico, quando todas as outras tentativas fracassaram. Por fim, cabe perguntar de que modo o elemento fantástico de venda da sombra que o protagonista empreende no início do enredo dialoga com o questionamento proposto neste artigo.

\section{Pertencimento no microcosmo social do vilarejo}

A novela de Chamisso já foi objeto de vários estudos, todos eles especialmente interessados em decodificar o aspecto maravilhoso inerente à perda da sombra. Ler essa novela com foco no pertencimento, portanto, implica antes de mais nada tentar entender esse aspecto simbólico, a partir das lógicas de inclusão e exclusão, proposto por este artigo. A impossibilidade de pertencer fica definitivamente explícita no momento em que o protagonista, Peter Schlemihl, não é mais dono de sua sombra. Contudo, já antes de renunciar à sua sombra a fim de obter a bolsa da fortuna de Fortunado, ele já passa por experiências que questionam justamente seu desejo de inclusão.

Os primeiros elementos que marcam a diferença do protagonista surgem no início da narrativa, indicando sua marginalização e sua incapacidade de arraigamento. Sua permanência na hospedaria o coloca num lugar de transição por excelência e, nela, têm início suas tentativas de negociação de pertencimento. Nessa interação inicial com os nativos do vilarejo, Peter Schlemihl é alvo de um olhar inquisitivo, cujo esforço reside em definir seu lugar na hierarquia social: "o empregado mediu-[lhe] com o olhar, de cima a baixo, e conduziu-[lhe] ao sótão" (CHAMISSO, 2003, p. 29). Esse olhar, que se destaca pelo interesse voltado à sua aparência física e à estrutura semiótica de sua indumentária, rapidamente o situa, e esse posicionamento 
revela ao estalajadeiro o tipo de acomodação que considera adequada para seu hóspede. Com efeito, o ambiente do sótão traz consigo a significância de um local isolado dos demais cômodos, frequentemente destinado ao armazenamento de objetos em desuso, isto é, que não fazem parte das interações cotidianas. Em contraste, existe a interação futura, quando Schlemihl já possui a bolsa dinheiro e troca de hospedaria. Sua nova condição de posse lhe permitirá determinar o espaço que irá ocupar: "pedi para que me dessem os melhores quartos da frente" (CHAMISSO, 2003, p. 44).

Contudo, ainda quando não possui esta liberdade, mas já com a acomodação definida, Schlemihl busca se integrar às malhas sociais que predominam naquele contexto. Com efeito, seu deslocamento a esse vilarejo ocorre por conta de uma carta de recomendação, endereçada a um membro, com vasto capital econômico. Para sua aproximação, o personagem se veste "cuidadosamente com [suas] melhores roupas" (CHAMISSO, 2003, p. 30) e é recebido por Thomas John, o anfitrião, "como um rico costuma acolher a um pobre diabo, até mesmo [virando-se] para [ele], sem contudo se afastar dos demais" (CHAMISSO, 2003, p. 30). O acolhimento de Schlemihl não é caloroso e, através do posicionamento físico do anfitrião, que não se desloca, percebe-se que de sua parte não há um empreendimento de esforços para gerar uma configuração de pertencimento. De fato, Thomas John não confere importância à presença de Schlemihl. Ele abre a carta de recomendação, mas não interrompe o fluxo de sua conversa, para dedicar sua atenção ao hóspede. Nessa intersecção, começam a ser traçados os vetores que configuram as regras de inclusão e exclusão, pautadas estas pelo princípio da riqueza material, com suas mais diversas semióticas que indicam o poder aquisitivo do indivíduo.

Ansiando por aceitação, Schlemihl procura adaptar as estratégias de encenação identitária, para que sua representação pública produza elementos de confluência com o grupo a que deseja pertencer. Uma dessas estratégias é a adaptação de seu discurso, que o leva a concordar com uma proposição do anfitrião de que “[q]uem não possui pelo menos um milhão é [...] um patife!” (CHAMISSO, 1813, p. 30). Com esta afirmação, Thomas John externaliza o pré-requisito para a participação neste ambiente, isto é, o imperativo do poder econômico como bilhete de entrada e como base para qualquer mostra de respeito.

Flores (1974) comenta que, por não conhecermos sobre o passado de Schlemihl, podemos assumir que, em sua chegada neste microcosmo social, ele é movido pela ingenuidade. Esta ingenuidade se dá pela possível falta de conhecimento sobre prioridades e valores, consequentemente, sobre normas de socialização. Neste caso, essa ingenuidade rege a forma como o personagem busca se adaptar ao seu redor, sem refletir sobre sua adaptação. O anseio 
por pertencimento e, consequentemente, a assimilação irrefletida desse discurso impedem que Schlemihl questione a forma como valores são atribuídos nesse contexto social. King (2016), ao falar sobre os objetos de troca (a sombra e alma), caracteriza a perda destes pontos individuais de Schlemihl como uma forma de desintegração de sua identidade. Em nome do pertencimento, ele está disposto a ignorar elementos importantes de sua individualidade e adaptar sua visão de mundo para que isso sirva como moeda de troca para sua ascensão e visibilidade.

Com base em sua experiência na estalagem e, sobretudo, no contexto social que ele encontra na festa de Thomas John, Schlemihl entende que o caminho para o pertencimento reside na aquisição de capital econômico. É essa convicção que o leva a aceitar o negócio proposto pelo desconhecido, trocando sua sombra pela bolsa de dinheiro. Nela, ele vislumbra a chance de ascender socialmente e possuir uma oportunidade para se aproximar de agrupamentos sociais, aos quais confere importância.

No entanto, após ser identificado como alguém sem sombra e não ser aceito pelo grupo social de Thomas John, Schlemihl parte com sua nova fortuna para outro local. No caminho, o personagem é confundido com um rei:

E eu continuava sem saber o que significava tudo aquilo e por quem era tomado. Encarreguei Rascal de fazer averiguações. Contaram-lhe que haviam tido informações seguras de que o bom rei da Prússia viajava pelo país sob nome de um conde. [...] Mas a coisa pareceu tão divertida ao malandro do Rascal que ele fez o possível, valendo-se de um discurso severo, para reforçar a crença daquela boa gente. Apresentou-me um relato bastante cômico e, vendo-me contente, caprichou ao falar da maldade que cometera. - Devo confessar? Ainda que em tais circunstâncias, o fato de ter sido confundido com aquele ser venerado não deixou de lisonjear-me (CHAMISSO, 2003, p. 62).

Apesar da inicial desconfiança de Schlemihl, por não saber do que trata a multidão, a situação de ser confundido com alguém de grande importância o induz a não contar a verdade. Mesmo sabendo que esta narrativa de representação não surge apenas de uma confusão momentânea, já que é alimentada por Rascal, Schlemihl não empreende esforços em contestála, em função do afeto que lhe é direcionado. A experiência de sentir-se acolhido faz com que Schlemihl se instale naquela comunidade. Nisto, o protagonista dá continuidade à narrativa, mesmo quando há a possibilidade de esclarecer o engano: "eu tinha sido rei e precisava 
continuar sendo rei para todos os efeitos [...]. Apenas, ninguém sabia ao certo qual. [...] Mas o conde Peter continuou sendo aquele que era" (CHAMISSO, 2003, p. 65).

Esse contexto the oferece novas formas de interação social e, com isso, de suprir sua necessidade de aceitação. Em parte, a implementação dessa narrativa deriva da vaidade do protagonista e dos potenciais de prazer que depreende dessa configuração. Para isso, não hesita em competir com antagonistas, como o comerciante, a fim de estabelecer hierarquias de poder econômico: "para evitar a desmoralização, teve novamente de declarar falência e se retirar para além das montanhas" (CHAMISSO, 2003, p. 65). Desta forma, o ouro de Schlemihl permite que demarque, de forma indireta, o local que considera digno de ocupação para sua narrativa, a saber, o centro do balneário.

Contudo, conforme os interlocutores constatam a falta de sombra, a desmoralização de Schlemihl acaba sendo inevitável. O posicionamento do criado Raskal de que "um criado pode ser um homem muito honrado e pode não querer servir a uma pessoa sem sombra" (CHAMISSO, 2003, p. 74) expressa o momento em que tanto a narrativa identitária de conde, quanto a superioridade hierárquica produzida por sua fortuna não bastam para que o personagem deixe de ser desqualificado da possibilidade de pertencer àquele espaço social, reforçando a ideia de que "the loss of his shadow is interpreted as a mark of insurmountable otherness" (KING, 2016, p. 35). Nessa virada, o poder econômico se revela impotente no esforço de obtenção da sensação de pertencimento.

Schlemihl abandona o balneário, se desfaz da bolsa de dinheiro e revê sua atitude marcada por vaidade:

Fiquei sem sombra e sem dinheiro, mas um peso opressivo tinha sido tirado de meu peito e sentia-me sereno. [...]

Analisei-me do ponto de vista da nova condição que deveria assumir no mundo. Minha roupa era bastante modesta. Tinha a velha e negra kurtka que eu usava em Berlim [...]. No mais, trazia sobre a cabeça um boné de viagem e nos pés velhas botas. Levantei-me, cortei naquele mesmo lugar um cajado como recordação e imediatamente dei início à minha peregrinação (CHAMISSO, 2003, p. 108).

A mudança de Schlemihl não se dá apenas por sua troca de roupas, já que dando início a um processo de peregrinação, se desfaz da ambição de se enraizar em um espaço definitivo. O personagem se dá conta do hiato terminante causado pela falta de sombra e, com isso, da impossibilidade inexorável de pertencimento. Para dar início a este novo ciclo, retoma sua 
antiga vestimenta com a humildade esquecida e recupera a narrativa de identidade inicial, de quando não possuía recursos econômicos e a ascensão social não pairava no horizonte. Nessa mudança de vetores, se estabelecem novos valores na concretização de sua representação identitária.

\section{Pertencimento na esfera afetiva}

De forma paralela ao desejo de pertencimento de classe, o protagonista também almeja estabelecer relações afetivas. A concretização desses laços afetivos implica a aceitação do personagem e a construção de uma narrativa conjunta com outros personagens. Nisso, sua narrativa de identidade pública é conflituosa, uma vez que não pode assumir determinados aspectos de sua configuração individual, dada a estigmatização da ausência de sombra. Dessa forma, o nível de aproximação de outros personagens na esfera privada de Schlemihl acaba sempre sendo dosado e ponderado, a partir dessa lógica individual.

Nesse cenário, a alteração da condição social do protagonista para um estado em que a situação econômica já não representa mais um obstáculo não elimina automaticamente o imperativo da negociação de pertencimento. Com sua riqueza em evidência, sua visibilidade aumenta proporcionalmente. Desta forma, a falta de sombra passa a ser percebida com maior acuidade e como elemento passível de estigmatização:

Um maldito diabinho corcunda [...] percebeu logo que me faltava uma sombra e delatou-me aos berros a toda molecada escolar do bairro; imediatamente começaram a praguejar contra mim e a jogar-me lama: "Pessoas decentes costumam levar sombra junto quando saem ao sol." Para defender-me deles, lancei-lhes punhados de moedas de ouro e saltei para dentro de um carro de aluguel, ajudado por algumas almas piedosas (CHAMISSO, 2003, p. 44).

Schlemihl não tarda em ser alvo de um outro olhar caracterizado pela violência explícita. Parmentier (2005), comenta que é através das palavras e olhares dos outros que Schlemihl irá perceber a importância daquilo que perdeu. Nisso, a exclusão social de Peter independe de sua condição econômica, pois deixa de possuir uma característica considerada comum a todos, a sombra. A única estratégia em que consegue atinar é o dinheiro, que agora não lhe falta. Sua posse lhe permite amenizar o impacto da exclusão. Por meio dele, ele consegue, ao menos, desviar o foco de sua alteridade e canalizar a atenção, antes voltada para a diferença, para a 
obtenção do dinheiro que joga para distrair o grupo. Parmentier comenta que são as palavras e olhares destes indivíduos externos que impedem o personagem de usufruir tranquilamente de sua aquisição.

Ao identificar essa nova forma de exclusão, Schlemihl entra em contato com um pintor, para que este pinte uma nova sombra, como tentativa, por meio da arte, de produzir uma presença, cuja concretude condiciona o pertencimento. Contudo, a resposta do pintor não atende as expectativas de Schlemihl:

A sombra postiça que eu poderia pintar-lhe [...] seria de tal natureza que ele a perderia de novo ao menor movimento — sobretudo em se tratando de alguém que tinha tão pouco apego à sua sombra de nascença, como se pode deduzir de sua narração. Quem não tem sombra, que não saia ao sol — essa é a coisa mais sensata e segura (CHAMISSO, 2003, p. 54).

O pintor se recusa a tentar produzir uma forma de amenizar sua diferença, destacando que não existe uma solução permanente para resolver o problema de Schlemihl. Seu conselho, portanto, reside na busca pela invisibilidade social. Nisso ele evita qualquer forma de envolvimento afetivo, especialmente no exercício da empatia. Com efeito, a busca de Schlemihl por ajuda não desperta em outros personagens, com exceção de Bedel, a compaixão necessária para que se envolvam em sua causa. Svasek (2010, p. 873) pontua que "the lack of empathy increases the incomer's experience of non-belonging". Assim, a tentativa de construir uma ponte para sua aceitação é frustrada.

A utilização do dinheiro é a primeira de muitas estratégias de dissimulação, utilizadas por Schlemihl para atenuar a acuidade de sua diferença. Outros recursos vão surgindo conforme os riscos de exclusão vão se materializando. A exemplo destes recursos estão o empréstimo de sombra de Bedel, para "dissimular [sua] deformidade" (CHAMISSO, 2003, p. 56), a exposição de Peter apenas à noite, evitando o luar e a utilização de disfarces para cobrir o rosto (CHAMISSO, 2003, p. 48). Assim, ainda tentando ser aceito, Schlemihl "testa a opinião pública" (CHAMISSO, 2003, p. 48), para, no fim, constatar que o pertencimento se revela obtenível somente mediante o encobrimento da diferença.

Considerando essa condição, na qual tanto a ausência de sua sombra como as estratégias de dissimulação da diferença foram identificadas, o protagonista pondera sobre a motivação de seu desejo de pertencimento: 
Sentia muito bem que não podia demorar-me em um lugar onde já me tivessem visto sem sombra, onde poderia ser facilmente denunciado; talvez pensasse ainda apenas na maneira como havia me mostrado na casa do senhor John, e isto era-me uma lembrança opressiva. Por isso quis fazer lá um ensaio para poder apresentar-me em outros lugares com mais confiança e desembaraço. - Mas aconteceu uma coisa que me prendeu por um certo período à minha vaidade: esta é a parte do homem em que a âncora encontra o terreno mais firme. Justamente a bela Fanny, que voltei a encontrar, concedeu-me alguma atenção, sem contudo se lembrar de que já me tinha visto antes [...]. A minha vaidade era torná-la vaidosa de minha companhia, e mesmo com a maior boa vontade não conseguia empurrar essa embriaguez da cabeça para o coração (CHAMISSO, 2003, p. 56).

A vaidade, reconhecida como propulsora central de sua ação, faz com que o personagem continue buscando por participação em uma comunidade que reduz as virtudes de um indivíduo ao status social. Sem poder ter toda a gama de sua identidade revelada, Schlemihl precisa inventar uma nova narrativa do si que não remeta a seu passado e que consiga apagar o estigma da diferença. A vaidade ainda o impulsiona a manter as tentativas de negociar seu pertencimento nesse espaço social, apesar de todos os descaminhos necessários para a obliteração da diferença.

Com a partida de Peter, que o leva ao segundo momento de sua busca por pertencimento, vale ressaltar que a narrativa assumida pelo personagem ainda reflete características embasadas na posse de recursos econômicos. Sua imagem pública é estabelecida pela visibilidade que o ouro proporciona e sustentada por sua vaidade. Nessa fase, ele ainda não vislumbra a possibilidade de aceitar sua diferença como condição para a obtenção de um pertencimento que independe de outros, isto é, um pertencimento marcado pela consonância entre imagem do si e aceitação. Assim, o ouro e seus potenciais de interação social fornecem uma espécie de sucedâneo de pertencimento. Até certo ponto, o ouro permite construir relações afetivas que, por mais superficiais que sejam, fornecem algum tipo de gratificação emocional.

Isso ocorre no episódio em que Schlemihl chega ao balneário e se vê confundido com um rei. Ele busca enraizamento a partir de uma narrativa pautada por recursos econômicos, como discutido anteriormente. Ao mesmo tempo, contudo, um dos interesses que impulsiona Schlemihl a se fixar nesse local é a promessa de amor pela jovem Mina. O primeiro encontro dos dois é descrito da seguinte forma: 
A figura alta e delicada ajoelhou-se diante de mim, enrubescendo de pudor, e ofereceu-me, sobre uma almofada de seda, uma coroa tecida de louros, ramos de oliveira e rosas, ao mesmo tempo que falava alguma coisa de majestade, veneração e amor - palavras que eu não compreendia, mas cuja sonoridade mágica inebriou os meus ouvidos e meu coração. [...] E essa cena, caro amigo, em pleno sol! Ela continuava ajoelhada a dois passos de mim e eu, sem sombra, não pude transpor tal abismo, não pude jogar-me diante do anjo. [...] Fui obrigado a esconder minha vergonha, meu medo e meu desespero no fundo do carro (CHAMISSO, 2003, p. 61).

O abismo que os separa não se concretiza apenas pela falta de sombra, ele se revela, sobretudo, no momento em que o protagonista tenta vislumbrar um futuro conjunto, marcado pela confluência afetiva. O ouro, contudo, lhe permite atender às expectativas sociais da família, o que o incita a não desistir de Mina, mas reconhecendo que "o amor [leva-o] a penetrar criminosamente no destino de um outro ser" (CHAMISSO, 2003, p. 94), e sabendo também que estaria "pervertendo aquele anjo com o egoísmo traiçoeiro, iludindo e roubando-lhe a alma pura" (CHAMISSO, 2003, p. 66). Mina corresponde seu investimento afetivo, mas Schlemihl se dá conta de que sua manutenção exige uma exposição do si que não encobre a alteridade, por mais radical que seja.

A tentativa de estabelecer uma narrativa conjunta com Mina, para suprir seu desejo de pertencimento afetivo, necessita, portanto, de uma troca recíproca de informações pessoais. Somente com a exposição franca de suas narrativas identitárias, seria possível dar continuidade ao projeto de vida em conjunto. Contudo, como o protagonista parece pressentir ao utilizar a imagem do abismo, a felicidade se torna dor quando Mina descobre que Schlemihl não tem sombra. Ainda assim, é apenas quando Raskal trai o protagonista, revelando aos pais de Mina a falta de sombra, que Schlemihl se vê impedido de concretizar seu casamento: "[o]s pais, iludidos pela encenação, fizeram de tudo para concluir o negócio o mais rápido possível, e a farsa vulgar terminou em escárnio" (CHAMISSO, 2003, p. 60).

Com isso, os potenciais de pertencimento baseados em afetividade são dissolvidos. $\mathrm{O}$ protagonista conclui: "Estava, como Faffner junto ao seu tesouro, distante de todo apoio humano, definhando com o ouro pelo qual não tinha amor nenhum, mas que amaldiçoava, pois por sua causa me via apartado da vida" (CHAMISSO, 2003, p. 53). Com o estigma da diferença à mostra, os recursos econômicos tampouco podem evitar sua exclusão do grupo. Mais impactante que isso, sua alteridade também impede a estabilização de relações afetivas que 
pudessem fornecer a sensação de pertencimento. Com isso, Schlemihl não está excluído somente do pertencimento de classe social, ele se vê em degredo, sobretudo, da comunidade daqueles que vislumbram um futuro conjunto, pautado por uma base afetiva.

\section{Busca por alternativas de pertencimento}

Ao constatar a impossibilidade de manutenção de práticas voltadas para a satisfação de sua vaidade e decidido a livrar-se do ouro como instrumento de onipotência, Schlemihl dá início à sua peregrinação pelo mundo. Distante da vigilância social de espaços mais restritos e sem o policiamento daqueles que o conhecem, ele, de certo modo, parece se prometer a chance de acolhimento e, com isso, de uma configuração de pertencimento. Contudo, também essa tentativa acaba sendo frustrada, pois mesmo aqueles interlocutores que apresentam certa benevolência acabam não suportando sua alteridade, na falta de sombra.

Assim, ao encontrar em seu caminho solitário um viajante que segue na mesma direção, o protagonista vislumbra momentaneamente um potencial de troca, em que seu interlocutor se parece disposto a compartilhar informações e histórias, a fim de dar início a uma narrativa conjunta. Contudo, após perceber a falta de sombra, o viajante muda seu rumo sem quaisquer explicações, o que o protagonista percebe com uma acuidade dolorosa: "Continuei meu caminho com o coração entristecido e dali em diante não procurei mais a companhia de nenhuma pessoa" (CHAMISSO, 2003, p. 109). Fica evidente a partir desta interação que mesmo os indivíduos que não iriam se aproximar movidos pelo ouro não desejam estar associados a alguém que não possui sombra. Sua alteridade rompe continuamente todo esforço de aproximação.

Para desviar o foco de sua dor, Schlemihl busca por alternativas para repensar sua configuração existencial. A primeira, dentre elas, reside na tentativa de silenciar os questionamentos que lhe afloram à mente, por meio da extenuação do corpo: "eu chegara à conclusão de que somente um trabalho extenuante poderia proteger-me de meus pensamentos destrutivos" (CHAMISSO, 2003, p. 110). Assim, além de representar uma alternativa possível para seu sustento e consequentemente também para a bolsa de ouro, seu trabalho em uma mina de ouro subterrânea também forma a base para seu esforço de repressão. A exaustão do corpo torna-o menos sensível para o impacto dos pensamentos dolorosos que acompanham sua falta de pertencimento. 
Nesse contexto, ainda a caminho da mina, o personagem é obrigado a se desfazer da última parte de seu vestuário que ainda remonta a seu passado: suas botas. Para resolver isso ao comprar um velho par de botas, o personagem adquire, sem saber, seu passaporte para experimentar o mundo de nova forma. Schlemihl demora alguns momentos para se dar conta de como a paisagem, vegetação e população se alternavam de forma abrupta ao redor de si após adquirir as botas de sete léguas. Com essa virada repentina em seu destino, Schlemihl identifica uma nova forma de conceber sua existência:

Em muda devoção, caí de joelhos e verti lágrimas de gratidão, pois de repente o meu futuro pareceu nítido diante de minha alma. Excluído da sociedade humana por um erro da juventude, fui, como compensação, destinado à natureza que eu sempre amei; a terra foi-me dada como um rico jardim, o estudo como direção e força de minha vida e, como meta, a ciência. Não foi uma decisão tomada por mim. Desde então procurei configurar fielmente [...] aquilo que [...] surgia diante de meu olho interior; e minha auto-satisfação dependia da coincidência do que era configurado com a imagem primordial (CHAMISSO, 2003, p. 115).

Reconhecer o esplendor ao seu redor possibilita a Schlemihl identificar em si uma antiga configuração afetiva que havia perdido importância, isto é, a satisfação por estar em contato com a natureza. Assim, seu olhar se volta para a ciência, instaurando uma nova forma de realização pessoal, a qual se dá através da aquisição de conhecimento. Nisso, Schlemihl não se restringe somente a adquirir conhecimento, como nova forma de estar no mundo, o personagem também se envida esforços para compartilhá-lo: "Tomarei providências para que antes de minha morte meus manuscritos sejam entregues à Universidade de Berlim" (CHAMISSO, 2003, p. 126). Conforme o protagonista compartilha seus manuscritos com a comunidade científica, também estabelece uma nova maneira de pertencer. Por um lado, a aquisição de conhecimento se revela como forma de reconfiguração de sua permanência no mundo e de sua organização teleológica. Por outro lado, ao expressar o desejo de compartilhar esses conhecimentos, ele também indica seu anseio de pertencer a uma comunidade.

Num primeiro momento, as duas modalidades parecem finalmente proporcionar aquilo que Schlemihl procura há muito tempo, isto é, a sensação de pertencer. Passado o momento de euforia do narcótico de pertencimento, a dedicação à ciência se revela igualmente vazia. Com efeito, esse sucedâneo de pertencimento não supre as necessidades afetivas do personagem, apesar de ter encontrado formas provisórias de satisfação. A vida solitária definitivamente não 
proporciona a troca de afeto pela qual o protagonista anseia. Buscando suprir esta necessidade, o personagem se estabelece em uma caverna de Tebas e adota um animal de estimação:

Como sucedâneo para felicidade ausente, tinha o tabaco e, em lugar do carinho e da convivência humana, o amor de um cão fiel, que guardava minha gruta em Tebaida e que saltava feliz sobre mim [...], fazendo-me sentir de maneira genuinamente humana que eu não estava só no mundo (CHAMISSO, 2003, p. 120).

Os rituais solitários do lar e o amor de seu cão trazem a Schlemihl maneiras de amenizar a solidão. Apesar do estilo de vida caracterizado por constantes deslocamentos, em que busca conhecimento nas mais variadas partes do mundo, Schlemihl forma uma espécie de arraigamento nessa gruta. Por mais problemática e precária que seja, essa configuração espacial permite ao personagem que siga seu percurso existencial de uma forma mais tranquila, menos voltada para a rememoração angustiante de experiências dolorosas. Nessa leitura, o espaço da gruta representa um espaço de fuga e de repressão da dor, produzida pela impossibilidade de obtenção de pertencimento. Mas ao mesmo tempo, ao fornecer a estabilidade de rituais, de ordem e proporcionar um lugar que satisfaz o anseio de retorno, ela também representa uma alternativa de pertencimento. No fim, também aqui trata-se de um sucedâneo, precário e frágil, que demanda do protagonista uma constante administração afetiva, a fim de evitar que a dor da exclusão volte à superfície.

\section{Considerações finais}

A trajetória de Schlemihl tem como marca a busca por pertencimento. Para obter o passaporte de aceitação em meio a um grupo social mais abastado, ele se está disposto a vender sua sombra. Com a venda, ele obtém os recursos necessários para concretizar diversas formas de encenação do si. O que ele experimente a partir desse momento, contudo, revela que recursos econômicos não satisfazem o anseio de pertencimento, uma vez que sua alteridade o impede de ser aceito nos diferentes círculos em que transita. Essa exclusão se concretiza no círculo inicial do vilarejo, mas também volta em círculos mais restritos, nos quais busca por afeto. Em todos eles, o estigma simbólico da ausência de sombra incita à negação de concessão de pertencimento. 
Com as botas e após reconhecer a impossibilidade de pertencimento nos moldes daquilo que qualquer indivíduo obtém num percurso tradicional, ele passa a investir seus esforços na aquisição de conhecimentos e na construção de uma casa alternativa como espaço de pertencimento. Ambos, contudo, se revelam como sucedâneos, no fim, insuficientes para satisfazer plenamente seus anseios de pertencimento. Com isso, a sombra assume um significado duplo. Num primeiro momento, a sombra é o estigma que impede a aceitação, uma vez que o reconhecimento da alteridade imediatamente desencadeia o afastamento dos interlocutores com os quais Schlemihl busca negociar formas de pertencer. Por outro lado, essa mesma sombra parece representar uma existência às margens da luz, isto é, um percurso existencial desprovido dos potenciais de sentido que a afetividade pode proporcionar. Nesse sentido, o texto de Chamisso antecipa uma experiência recorrente em muitos textos dos fluxos migratórios, captando uma dinâmica central da interação humana.

\section{Referências}

CHAMISSO, Adelbert. A história maravilhosa de Peter Schlemihl. Tradução: Marcus Vinicius Mazzari. São Paulo: Estação Liberdade, 2003.

FISCHER, Robert. Adelbert von Chamisso. Weltbürger, Naturforscher und Dichter. Berlin: Klopp, 1990.

FLORES, Ralph. The Lost Shadow of Peter Schlemihl. In: The German Quarterly, v. 47, n. 4, 1974, p. 567-584.

KING, Christa K. Adelbert von Chamisso's "Peter Schlemihl" and the Quest for the Self. In: FITZSIMMONS, Lorna (ed.). Faust Adaptations from Marlowe to Aboudoma and Markland. West Lafayette: Purdue University Press, 2016, p. 31-45.

LAHNSTEIN, Peter. Adelbert von Chamisso. Der Preuße aus Frankreich. München: List, 1984.

LANGNER, Beatrix. Der wilde Europäer. Adelbert von Chamisso. Berlin: Matthes \& Seitz, 2008.

SVAŠEK, Maruška. On the Move: Emotions and Human Mobility. In: Journal of Ethnic and Migration Studies, v. 36 n. 6, 2010, p. 865-880.

PARMENTIER, Sabine. Adelbert von Chamisso e o narcisismo primário. Tradução de Pedro Henrique Bernardes Rondon. In: Ágora, v. 8, n. 2, 2005, p. 207-235. 
PFAFF-CZARNECKA, Joanna. From 'Identity' to 'Belonging' in Social Research: Plurality, Social Boundaries, and the Politics of the Self. In: ALBIEZ, Sarah; CASTRO, Nelly; JÜSSEN, Lara; YOUKHANA, Eva (eds.). Ethnicity, Citizenship and Belonging: Practices, Theories and Spatial Dimensions. Etnicidad, ciudadanía y pertenencia: prácticas, teoría y dimensiones espaciales. Frankfurt am Main: Vervuert, 2011, p. 199-219. 